\title{
Cardiogenic stroke in the young
}

\author{
Anetta Lasek-Bal', Zofia Kazibutowska² \\ 1Stroke Unit, Medical University of Silesia Hospital No. 7, Professor Leszek Giec Upper Silesian Medical Centre, Katowice, Poland \\ 2Department of Neurology, Medical University of Silesia Hospital No. 7, Professor Leszek Giec Upper Silesian Medical Centre, Katowice, \\ Poland
}

Postep Kardiol Inter 2012; 8, 2 (28): 134-137

DOI: $10.5114 /$ pwki.2012.29654

\begin{abstract}
Stroke in young individuals often has a cardiogenic etiology. The type of cardiac abnormality and the risk of potential embolism that is associated with it are different in comparison with the ones that occur in later decades of life. The diagnostic procedure in this group of patients should include comprehensive cardiological evaluation, including rhythm and structural abnormalities of the heart. In a significant proportion of young stroke patients, the etiological factor and the risk of recurrence are not established in spite of comprehensive evaluation. It is worth paying attention to abnormalities regarding the structure of the heart, which are treated as moderate- or low-risk abnormalities with undetermined real significance for stroke. The authors carried out a systematic analysis of cardiac diseases with established and potential significance for the development of stroke in young individuals. The results of the latest studies and experts' opinions were taken into account. The paper presents doubts arising in the course of diagnostic procedures, making the selection of appropriate methods of secondary prevention of stroke more difficult.
\end{abstract}

Key words: stroke, patent foramen ovale, cardioembolism

\section{Introduction}

The distribution of risk factors for stroke shows age dependence. Cardiogenic etiology is present in $20 \%$ of young people with stroke [1]. The share of heart disease in causing cerebral ischemia, however, may be more serious due to the fact that in approximately 20-30\% of patients it is impossible to clearly determine its cause $[1,2]$. The diagnosis of cardio-embolic stroke relates to patients with embolic stroke of the cerebral or cerebellar cortex, and specific heart disease with no other causes of stroke [3]. The risk of cerebral embolism varies according to the pathology of the heart. In 1997 Welch et al. presented the classification of the causes of cardiogenic strokes by making their division associated with absolute and relative risk of stroke occurrence [4]. The causes of absolute risk of cerebral embolism according to the division are: atrial fibrillation, mitral stenosis, mechanical heart valves, early myocardial infarction, infective endocarditis, atrial myxoma and the presence of thrombus in the left ventricle without the coexistence of the above-mentioned abnormalities. The relative risk factors of cardiogenic cerebral embolism according to the Welch et al. classification include mitral valve prolapse, patent foramen ovale (PFO), atrial septal aneurysm and segmental left ventricular dysfunction. The degree of risk of cardiogenic stroke occurrence in these latter cases is the subject of controversy. Participation of cardio-embolism in the pathogenesis of stroke and the incidence of cryptogenic strokes in young people are shown in the table (Table 1) with inclusion of the most recent findings $[1,2,5,6]$. The incidence of cardio-embolic strokes is similar in the group of young and old people, but its pathogenesis is different.

Clinical situations associated with potential risk of cardio-embolic stroke in the young are presented below. For the purposes of this study an age below 55 years was considered as a "young age," which is consistent with the criterion adopted in most studies referred to by the authors.

\section{Patent foramen ovale}

Prevalence of PFO in patients over 45 years of age is about $24 \%$ [7]. The incidence and the size of leakage due to its presence decrease with age [8]. The importance of the presence of PFO for the occurrence of stroke remains undetermined. It was found that young patients with

\section{Corresponding author:}

Anetta Lasek-Ball, Stroke Unit, Medical University of Silesia Hospital No. 7, Professor Leszek Giec Upper Silesian Medical Centre, 45/47 Ziołowa, 40-635 Katowice-Ochojec, Poland, tel.: +48 3235983 06, fax: +48 32202 95 92, e-mail: balanett@poczta.onet.pl Praca wpłynęła: 23.02.2012, przyjęta do druku: 28.05.2012. 
Table 1. Frequency of cardioembolic stroke in young people

\begin{tabular}{|c|c|c|c|c|c|}
\hline Authors & Study period & Age of patients [years] & Number of patients & Cardio-embolism [\%] & Unknown cause [\%] \\
\hline Cerrato et al., 2004 & $1994-2011$ & $16-49$ & 273 & 24 & 24 \\
\hline Nedeltchev et al., 2005 & $1997-2000$ & $16-45$ & 203 & 24 & 33 \\
\hline Varona et al., 2007 & $1974-2002$ & $15-45$ & 272 & 18 & 36 \\
\hline Putaala et al., 2009 & 1994-2007 & $15-49$ & 1008 & 20 & 33 \\
\hline
\end{tabular}

stroke have significantly higher incidence of PFO in comparison to healthy subjects $[9,10]$. It was also found that patients with stroke and persistent foramen ovale were younger and had a lower number of traditional risk factors for cerebral vascular disease in comparison to patients with stroke but without the presence of PFO [11]. There is no doubt about the statistical relationship between coexistence of PFO and stroke; however, this does not mean a cause and effect relationship. Given the prevalence of PFO based for example on the results of echocardiography, it seems likely that coexistence of PFO and stroke is coincidental, as the presence of PFO in the group of all patients suffering from stroke is estimated at around 30\% [12]. There is disagreement among authors on the importance of the relationship between the size of the leak and the number of emboli for cerebral ischemia and whether the size of the PFO is important for recurrence of stroke $[11,13]$. Results of the multicenter CODICIA study involving a Spanish population did not confirm this relationship [14]. The presence of PFO is a factor facilitating the achievement of cerebral circulation by paradoxical emboli, which is hemodynamically justified, but in practice in the overwhelming majority of patients with PFO and stroke the origin of emboli cannot be determined. Emboli may be derived from the pelvic veins. It is also likely that the mechanism of paradoxical embolism is not the main one, which points towards other pathomechanisms of brain perfusion abnormalities associated with the presence of PFO such as blood clot formation in the septal wall or within the PFO, which may be suggested by fibrin deposits found during cardiac surgery. There is a theory suggesting increased susceptibility of the atria to cardiac arrhythmias, including clinically silent ones, caused by stretching of atrial walls by patent foramen ovale or atrial septal aneurysm [15]. In fact, it is not the presence of patent foramen ovale but the other pathologies "induced" by its presence that could be the cause of cerebrovascular disease [15-18]. Another issue is the coexistence of PFO and coagulation disorders in young patients with stroke. A cumulative effect of factor $\checkmark$ Leiden or prothrombin gene (G20210A) mutations and the presence of PFO for the occurrence of cerebral circulation disorders is emphasized. In the studies of Botto et al. and Pezzini et al. these mutations occurred significantly more often in patients with stroke and PFO as compared to healthy individuals $[19,20]$. Coagulation disorders in young patients with stroke are of minor importance, which however increases with the presence of other pathologies, such as PFO.

Patent foramen ovale with concomitant atrial septal aneurysm, migraine or coagulation disorders is an example of interaction of risk factors having a small or doubtful potential action if present in isolation. According to the TOAST system of classification of risk factors of stroke, patent foramen ovale was categorized as medium-risk pathology of cerebral embolism [21]. In the more recent A-S-C-O system it was placed among the causes of cardioembolism of uncertain significance for the cerebral circulation [22].

Analysis of risk factors for cryptogenic stroke in young patients in the Helsinki Young Stroke Registry has not demonstrated the relevance of the presence of PFO. It is worth noting, however, that the incidence of this atrial septal abnormality in a group of more than 1,000 patients was lower than in the population, which is explained by the authors by insufficient number of properly performed transesophageal echocardiographic examinations [1].

In patients with ischemic stroke or transient ischemic attack who have patent foramen ovale it is reasonable to start antiplatelet therapy (class Ila, level B). There are insufficient data to determine the importance of anticoagulant therapy (IIb, B) or surgical intervention (IIb, C) [23]. Ongoing randomized studies compare surgical correction and conservative treatment of PFO in young patients after stroke. The preliminary results of the CLOSURE 1 study have not confirmed a significant advantage of intervention over conservative treatment.

\section{Atrial septal aneurysm}

Another anomaly of the interatrial septum is aneurysm (ASA), which often co-exists with PFO, and is considered as a potential risk factor for the occurrence of first and recurrent stroke [9, 10, 24-26]. Aneurysms often coexist with larger leaks and increase the tendency for thrombus formation, which could explain the recurrent nature of symptomatic cerebral embolism. The presence of ASA was found in $2 \%$ of the young adults with the first stroke from the Helsinki Young Stroke Registry and coexistence of the aneurysm and PFO was confirmed in $7 \%$ of these patients [1]. In the prospective FOP/ASA study the annual risk of recurrent stroke in patients under 55 years of age with PFO and ASA was $4 \%$ and with PFO only $0.6 \%$ [27]. The results of the PICSS study do not confirm the signifi- 
cant relation of these pathologies of the interatrial septum with an increased risk of a recurrent stroke [28]. The cited studies differed in terms of qualification rules and endpoints. It is worth noting that ASA accompanied by migraine was diagnosed in $34.4 \%$ of patients with stroke $<55$ years of (while migraine without ASA in the presented material occurred in $18.5 \%$ of cases) [11]. It is likely that there is reinforcement between factors of potential embolic and hemodynamic significance for cerebral circulation. Most authors classify ASA in the group of low or uncertain risk factors of stroke.

\section{Atrial fibrillation}

Atrial fibrillation $(\mathrm{AF})$ is responsible for a 5 -fold increase of the risk of stroke and thus it is a major cause of cerebral embolism. According to the studies on different ethnic populations, the incidence of atrial fibrillation increases with age and predominates in men in any age range. The incidence of atrial fibrillation in people up to 60 years of age is estimated to be $0.1-0.2 \%$, while in patients older than 80 years it is $9.1-11 \%$ [29-31]. The association of stroke with atrial fibrillation is found in $4 \%$ of young patients with stroke. Atrial fibrillation was found as a risk factor in $4.2 \%$ of patients below 49 years of age with the first stroke [1]. In about 1/5 of the cases AF coexisted with structural heart abnormalities, involving mainly the interatrial septum. It is believed that all types of AF (paroxysmal, persistent or permanent) are associated with similar risk of stroke [32]. It is worth mentioning about the so-called clinically silent cerebral infarctions in the course of atrial fibrillation found in neuroimaging studies and which can cause cognitive dysfunction [33].

The prevention of stroke in patients with atrial fibrillation should include anticoagulation (class I, level A). Antiplatelet therapy is recommended for patients who are unable to use oral anticoagulants (class I, level A) [23]. Closure of the left atrial appendage in patients with atrial fibrillation and recurrent cerebral accidents in spite of antithrombotic therapy can be a therapeutic option reducing the risk of stroke and its severe complications. The importance of occlusive methods for the secondary prevention of stroke is currently undetermined.

\section{Infective endocarditis}

Stroke as a consequence of embolism with vegetations is a major neurological complication of this heart disease and occurs in $9-23 \%$ of patients [34, 35]. Infective endocarditis constituted $3 \%$ of causes of cardio-embolic stroke in young people in the Helsinki Stroke Registry [1]. Both cerebral infarction and transient ischemic attack are associated with worse prognosis. In the study of Anderson et al. $42 \%$ of patients with infective endocarditis (IE) complicated by stroke died within a year of illness. Patients with stroke require anticoagulation except for hemorrhagic stroke, which is the reason for deferral of such therapy.
The presence of neurological complications is not a contraindication for cardiac surgery. Infective endocarditis is a condition excluding the use of intravenous thrombolytic therapy of stroke.

\section{Other causes of cardio-embolic strokes in the young}

Other causes of cardiogenic stroke in young patients include dilated cardiomyopathy, valvular heart disease, acute myocardial infarction, hypo- or akinesis of the left ventricular wall, atrial myxoma and endocardial fibrosis in the course of hypereosinophilia $[1,36]$. A cerebral incident may be the first clinical manifestation of thrombo-embolic complications of these diseases.

\section{Summary}

Although the nature and the impact of the risk factors of stroke vary across decades of age, cardiogenic embolism invariably plays an important role. A high percentage of strokes in young patients is attributed to PFO, while cardiac arrhythmias are becoming more important in people over 60 years of age. In a substantial proportion of young patients with stroke despite extensive diagnostics it is impossible to clearly identify the etiological factor or the risk of its relapse. In many cases, the cause of stroke is assumed to be a low risk pathology in which the management has not been specified. Results of the ongoing trials comparing conservative and occlusive treatment in patients with pathologies of the interatrial septum will help to develop optimal strategies for the prevention and treatment of stroke in this particular group of patients.

\section{References}

1. Putaala J, Metso AJ, Metso TM, et al. Analysis of 1008 consecutive patients aged 15 to 49 with first-ever ischemic stroke: the Helsinki young stroke registry. Stroke 2009; 40: 1195-1203.

2. Cerrato P, Grasso M, Imperiale D, et al. Stroke in young patients: etiopathogenesis and risk factors in different age classes. Cerebrovasc Dis 2004; 18: 154-159.

3. Adams HP Jr, Bendixen BH, Kappelle LJ, et al. Classification of subtype of acute ischemic stroke. Definitions for use in a multicenter clinical trial. TOAST. Trial of Org 10172 in Acute Stroke Treatment. Stroke 1993; 24: 35-41.

4. Welch KMA, Caplan MR, Reis DJ, et al. Primer on cerebrovascular diseases. Academic Press, San Diego 1997; 41: 148-162, 177: 719-724.

5. Nedeltchev K, der Maur TA, Georgiadis D. Ischaemic stroke in young adults: predictors of outcome and recurrence. J Neurol Neurosurg Psychiatry 2005; 76: 191-195.

6. Varona JF, Guerra JM, Bermejo F. Causes of ischemic stroke in young adults and evolution of the etiological diagnosis over the long term. Eur Neurol 2007; 57: 212-218.

7. Meissner I, Khandheria BK, Heit JA, et al. Patent foramen ovale: innocent or guilty? Evidence from a prospective population-based study. J Am Coll Cardiol 2006; 47: 440-445. 
8. Cotter PE, Martin PJ, Belham M. Improved sensitivity of transthoracic contrast echocardiography in the detection of rightto-left shunts. J Am Soc Echocardiogr 2010; 23: 578-579.

9. Lechat P, Mas JL, Lascault G, et al. Prevalence of patent foramen ovale in patients with stroke. N Engl J Med 1988; 318: 1148-1152.

10. Cabanes L, Mas JL, Cohen A, et al. Atrial septal aneurysm and patent foramen ovale as risk factors for cryptogenic stroke in patients less than 55 years of age. A study using transesophageal echocardiography. Stroke 1993; 24: 1865-1873.

11. Lamy C, Giannesini C, Zuber M, et al. Clinical and imaging findings in cryptogenic stroke patients with and without patent foramen ovale: the PFO-ASA Study. Atrial Septal Aneurysm. Stroke 2002; 33: 706-711.

12. Alsheikh-Ali AA, Thaler DE, Kent DM. Patent foramen ovale in cryptogenic stroke: incidental or pathogenic? Stroke 2009; 40: 2349-2355.

13. Steiner MM, Di Tullio MR, Rundek T, et al. Patent foramen ovale size and embolic brain imaging findings among patients with ischemic stroke. Stroke 1998; 29: 944-948.

14. Serena J, Marti-Fàbregas J, Santamarina E, et al. CODICIA, Rightto-Left Shunt in Cryptogenic Stroke Study; Stroke Project of the Cerebrovascular Diseases Study Group, Spanish Society of Neurology. Recurrent stroke and massive right-to-left shunt: results from the prospective Spanish multicenter (CODICIA) study. Stroke 2008; 39: 3131-3136.

15. Berthet K, Lavergne T, Cohen A, et al. Significant association of atrial vulnerability with atrial septal abnormalities in young patients with ischemic stroke of unknown cause. Stroke 2000; 31: 398-403.

16. Amarenco P. Underlying pathology of stroke of unknown cause (cryptogenic stroke). Cerebrovasc Dis 2009; 27 Suppl 1: 97-103.

17. Ranoux D, Cohen A, Cabanes L, et al. Patent foramen ovale: is stroke due to paradoxical embolism? Stroke 1993; 24: 31-34.

18. Mas JL Patent foramen ovale, atrial septal aneurysm and ischaemic stroke in young adults. Eur Heart J 1994; 15: 446-449.

19. Botto N, Spadoni I, Giusti S, et al. Prothrombotic mutations as risk factors for cryptogenic ischemic cerebrovascular events in young subjects with patent foramen ovale. Stroke 2007; 38: 2070-2073.

20. Pezzini A, Del Zotto E, Magoni M, et al. Inherited thrombophilic disorders in young adults with ischemic stroke and patent foramen ovale. Stroke 2003; 34: 28-33.

21. Adams HP Jr, Bendixen BH, Kappelle LJ, et al. Classification of subtype of acute ischemic stroke. Definitions for use in a multicenter clinical trial. TOAST. Trial of Org 10172 in Acute Stroke Treatment. Stroke 1993; 24: 35-41.

22. Amarenco P, Bogousslavsky J, Caplan LR, et al. New approach to stroke subtyping: the A-S-C-O (phenotypic) classification of stroke. Cerebrovasc Dis 2009; 27: 502-508.

23. Furie KL, Kasner SE, Adams RJ, et al. American Heart Association Stroke Council, Council on Cardiovascular Nursing, Council on Clinical Cardiology, and Interdisciplinary Council on Quality of Care and Outcomes Research. Guidelines for the prevention of stroke in patients with stroke or transient ischemic attack: a guideline for healthcare professionals from the American Heart Association/American Stroke Association. Stroke 2011; 42: 227-276.

24. Di Tullio M, Sacco RL, Gopal A, et al. Patent foramen ovale as a risk factor for cryptogenic stroke. Ann Intern Med 1992; 117: 461-465.

25. Pearson AC, Nagelhout D, Castello R, et al. Atrial septal aneurysm and stroke: a transesophageal echocardiographic study. J Am Coll Cardiol 1991; 18: 1223-1229.
26. Fox ER, Picard MH, Chow CM, et al. Interatrial septal mobility predicts larger shunts across patent foramen ovales: an analysis with transmitral Doppler scanning. Am Heart J 2003; 145: 730-736.

27. Mas JL, Arquizan C, Lamy C, et al. Patent Foramen Ovale and Atrial Septal Aneurysm Study Group Recurrent cerebrovascular events associated with patent foramen ovale, atrial septal aneurysm, or both. N Engl J Med 2001; 345: 1740-174.

28. Homma S, Sacco RL, Di Tullio MR, et al. PFO in Cryptogenic Stroke Study (PICSS) Effect of medical treatment in stroke patients with patent foramen ovale: patent foramen ovale in Cryptogenic Stroke Study. Circulation 2002; 105: 2625-2631.

29. Wolf PA, Abbott RD, Kannel WB. Atrial fibrillation as an independent risk factor for stroke: the Framingham Study. Stroke 1991; 22 : 983-988.

30. Furberg CD, Psaty BM, Manolio T, et al. Prevalence of atrial fibrillation in elderly subjects (the Cardiovascular Health Study). Am J Cardiol 1994; 74: 236-241.

31. Go AS, Hylek EM, Phillips KA, et al. Prevalence of diagnosed atrial fibrillation in adults: national implications for rhythm management and stroke prevention: the AnTicoagulation and Risk Factors in Atrial Fibrillation (ATRIA) Study. JAMA 2001; 285: 2370-2375.

32. Watson T, Shantsila E, Lip GY. Mechanisms of thrombogenesis in atrial fibrillation: Virchow's triad revisited. Lancet 2009; 373: 155-166.

33. Mattle HP. Long-term outcome after stroke due to atrial fibrillation. Cerebrovasc Dis 2003; 16 Suppl 1: 3-8.

34. Cabell CH, Pond KK, Peterson GE, et al. The risk of stroke and death in patients with aortic and mitral valve endocarditis. Am Heart J 2001; 142: 75-80.

35. Anderson DJ, Goldstein LB, Wilkinson WE, et al. Stroke location, characterization, severity, and outcome in mitral vs aortic valve endocarditis. Neurology 2003; 61: 1341-1346.

36. Sarazin M, Caumes E, Cohen A, et al. Multiple microembolic borderzone brain infarctions and endomyocardial fibrosis in idiopathic hypereosinophilic syndrome and in Schistosoma mansoni infestation. J Neurol Neurosurg Psychiatry 2004; 75: 305-307. 